\title{
Research on EFL Teaching Mechanism for College Learner Autonomy via Mobile Multimedia in Chinese Context
}

\author{
Huanhuan Ren ${ }^{1,}$, Chi Ma ${ }^{2, b}$ \\ ${ }^{1}$ Teaching and Research Institute of Foreign Languages, Bohai University, Jinzhou, 121013, China \\ ${ }^{2}$ Jinzhou Institute of Forestry Research, Jinzhou Forestry Bureau, Jinzhou, 121013, China

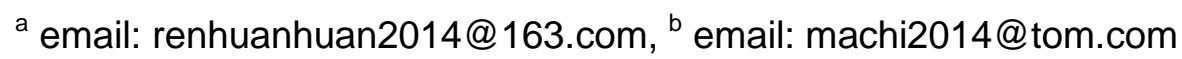

Keywords: EFL Teaching Mechanism; College Learner Autonomy; Mobile Multimedia

\begin{abstract}
The advent of mobile multimedia nurses great aspiration for the integrations of the relevant high technologies into English language curriculum. Mobile-multimedia assisted EFL teaching is theoretically based on constructivism, humanism and the input hypothesis, and practically supports the paradigm of the student-centered learning approach. Successful functioning of EFL teaching mechanism demands the integration of various technologies and the convergence of different autonomous learning stages. By integrating technologies into learning environment both horizontally and vertically, instructors can provide individual users with high level of control and interaction, and ultimately enhance learners' all-around English language capacities and English autonomous learning abilities in English learning.
\end{abstract}

\section{Introduction}

The advent of mobile multimedia creates new opportunities for English learning and instruction. In fact, the phrase of mobile multimedia has already been a buzzword in language learning for the past few decades. Mobile multimedia can help students exposed to rich and contextual language with a high degree of authenticity, and establish learning platform for their interaction from learner to computer, from learner to himself, and from learner to other learning agents. Then how to establish a language teaching mechanism for college learner autonomy via mobile multimedia? In this thesis, guiding principles and implementation approaches of EFL (English as foreign language) teaching mechanism via mobile multimedia are explored and analyzed, so that the EFL learner can play an active role in the learning process, and learner autonomy is more likely to be enhanced and developed in line with their needs and conditions under the influence of mobile multimedia.

\section{Developments of Mobile Multimedia and Mobile Learning}

The computer has found its way in language learning since the 1960s. Computer assisted language learning is the combination of computer technologies and linguistic theories, and can been divided into three distinct phases, namely structural CALL, communicative CALL and integrative CALL[1]. The evolvement of each phrase is owing to the developments of different technologies. For example, the advance in the technologies of multimedia computer and the Internet in 1990s are conducive to the last stage of CALL, integrative CALL, which focuses on the integration of language skills. In fact, the integration of high technologies into English language curriculum is providing English instructors a new teaching mode, different from the traditional 'chalk and talk' teaching environment.

With the development of information technology, especially with the quick advance in technologies of multimedia and hypermedia, multimedia aided English learning take place of traditional CALL, and English language learning via multimedia is taken seriously by both learners and instructors, for this new approach can create good environment for students' English language learning and autonomous learning. As it's stressed in College English Curriculum Requirements, drawn up by Ministry of Education of the People's Republic of China, "we should make full use of multimedia and the Internet technologies, and apply a new kind of teaching mode to take the place 
of the traditional teacher-centered mode, considering the rapidly increasing number of college students and the relatively limited teaching resources.”[2] Indeed, multimedia technologies bring about a new round of reform for modern English language teaching.

Then what is multimedia? Literally, multimedia means two or more media (e.g. text and graphics). In reality, the two media are normally sounds and moving pictures. According to the observation of language educations, a multimedia classroom usually consists of multimedia personal computer, amplifier and hi-fi acoustics system, overhead projector, screen, projecting apparatus, the Internet access and so on[3]. We can see that the appearance of multimedia plays a critical role in the revolution of college English language learning and instruction.

Mobile learning is a revolution of e-learning. Wireless Internet has provided such a boon to technology that huge evolvement and improvement have been made in the arena of education. Today's students have a variety of mobile technologies at their fingertips, and the application of mobile technologies and multimedia technologies enables learners get access to pervasive and convenient learning environment which people can't imagine before. With the emergence of mobile devices (e.g. smartphones) and the growth in operating systems, students have access to resources they want, and develop strong community of support for their English language learning. Instructors are also required to employ different approaches in educational setting and learn to be mobile-savvy themselves if they want to be adequately equipped in instruction. In a word, mobile technology is changing the way we live and it is beginning to change the way we learn.

\section{The Design Rules of EFL Teaching Mechanism via Mobile Multimedia}

Guiding rules of constructivism. Constructivism has been the main rationale of the foreign language teaching. Constructivism, an important branch of cognitive theory, holds that learning is a process that learners construct their knowledge initiatively instead of accepting knowledge passively. Specifically speaking, it's a philosophy of learning founded on the premise that, by reflecting on our experiences, we construct our own understanding of the world we live in. In Piaget's view, assimilation and accommodation occur to ensure students' cognitive development in the learning process. Assimilation is the process of using or transforming the environment so that it can be placed in preexisting cognitive structure, while accommodation is the process of changing cognitive structure in order to accept something from the environment[4]. His theories largely deal with the explanation about how to internalize the external knowledge structure into people's mental structure through their interaction with the outside world and environment. Humans are portrayed as constructive agents, and their meanings and knowledge are regarded as constructive products.

Accordingly, constructivist learning environment should be built to contribute to the learner-centeredness and emphasize authentic tasks in meaningful context rather than abstract instruction, so as to adjust learners' mental models to accommodate new experiences.

Dominating principles of humanism. More experts and researchers apply humanist theories to the modern language instruction. Humanism, as the mainstream theory during the Renaissance, pays more attention to human being and nature. The concept of humanism, as a psychological term, emphasizes the importance of inner world of human being and places the individual's thoughts, feelings and emotions at the forefront of all the human developments[5]. It expanded its influence throughout the 1970s and the 1980s, and developed as a rebellion against what some psychologists saw as the limitations of the behaviorist and psychodynamic psychology. Humanistic psychologists look at human behavior not only through the eyes of the observer, but through the eyes of the person doing the behaving. The theory also provides valuable insights for teachers, especially for those who are still employing the authoritarian teacher-centered approach in class. Language teachers are encouraged to play close attention to the development of the students' affective intelligence as well as their language ability, or say the teacher should organize what students think, what they need and what they know into the target language being learned, so as to achieve students' self-actualization and self-development in learning.

In a word, the humanist theory puts the focal point on the participation of 'a whole person', including the affective, cognitive and behavioral participation, and places the education of human 
beings on the top of the teaching agenda by denying any power or moral value superior to that of humanity.

Ideas from the input hypothesis. The input hypothesis provides the theoretical basis for mobile multimedia assisted instruction. The input hypothesis attempts to account for the learning processes in which languages are learned, namely it tries to answer a question that is important both theoretically and practically: how do we acquire language? Put forward by S.D. Krashen in the 1970s, the input hypothesis states that language learners move from $i$, our current level, to $i+1$, the next level along the natural order, by understanding input containing $\mathrm{i}+1$, a concept also known as comprehensible input, and this is a necessary (but not sufficient) condition. Here, 'understand' means that the acquirer is focused on the meaning and not the form of the message. We acquire, in other words, only when we understand language that contains structure that is 'a little beyond' where we are now. Central to the input hypothesis, it's comprehensive input which is both necessary and sufficient for language learning to take place. Language learners are supposed to intake comprehensive input both semantically and syntactically, so as acquire language in an all-around way, especially the ability to communicate effectively.

This hypothesis has a profound impact on the development of language learning and instruction, and it highlights the importance of using the target language in the classroom. By providing as much comprehensible input as possible, the teacher is able to create a more effective opportunity for language acquisition.

\section{The Implementation of EFL Teaching Mechanism via Mobile Multimedia}

The EFL teaching mechanism for college learner autonomy via mobile multimedia can be specifically implemented from two aspects, namely horizontal integration mechanism and vertical integration mechanism. The two aspects or directions can make the mechanism more comprehensive and more conclusive, and in some sense make the research more complete and more reasonable.

Horizontal integration mechanism

Horizontal integrating mechanism refers to the integration of physical space (i.e. in-class and out-of-class) and information space (i.e. online and offline) in the EFL teaching process. As is shown in Figure 1 (a), the combination of the elements in physical space and information space forms four subspaces, namely, A 'in-class - online', B 'out-of-class - online', C 'out-of-class offline', D 'in-class - offline’, and thereby different English autonomous learning behaviors can be generated and developed.

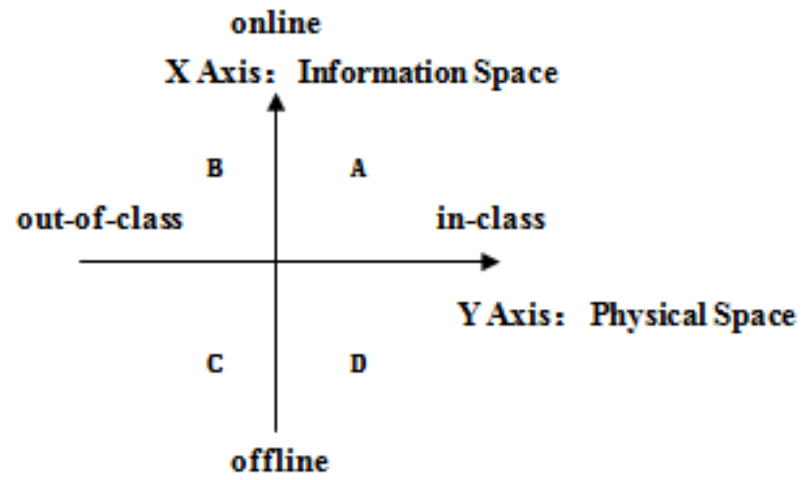

(a)

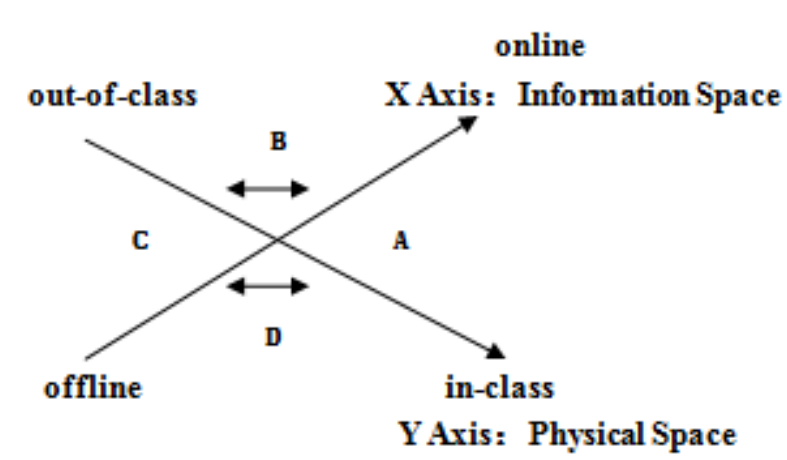

(b)

Fig.1. Horizontal integrating mechanism

The expansion of B subspace and D subspace, and the reduction of A subspace and C subspace, are more conducive to college learner autonomy in the EFL teaching process, as is shown in Figure 1 (b). Mobile multimedia can be fully leveraged both in class and after class, however more utilization of mobile multimedia after class leads to better learning outcomes, due to the out-of-class construction and internalization of knowledge and in-class interactive discussion and communication. Meanwhile college learner autonomy can be enhanced and developed with the 
intervention of the mobile multimedia. The spatial layout shown in Figure 1 (b) is advantageous and beneficial for college English autonomous learning behaviors in the EFL teaching process.

The synergy of the four subspaces, A 'in-class - online', B 'out-of-class - online', C 'out-of-class - offline', and D 'in-class - offline', in EFL teaching process, constitutes a horizontal integrating mechanism of the study. It's the integration of 'the first class' and 'the second class', which makes English learning more efficient and more continuous[6], especially with the help of mobile multimedia. The learning elements in each subspace are interdependent and constrained, and the integration of the four subspaces is to determine that the EFL teaching mechanism for college learner autonomy is a success, and is also the breakthrough of the proposed subject of the study .

It's worthy mentioning that the mobile multimedia is almost pervasive and English autonomous learning can take place everywhere. But college English learners are possible to be in a passive study status (i.e. offline) in the physical space, due to their lack of learner autonomy in language learning. That's why mobile-multimedia assisted English learning can't be as ideal as the technology of multimedia computer itself, as four subspaces exist in reality. However the leverage of mobile multimedia will greatly improve students' learning status (i.e. online) and facilitate their college English learner autonomy.

Vertical integration mechanism

Vertical integration mechanism refers to the integration of different autonomous learning stages in the EFL teaching process, namely motivation stage, objective stage, environment stage, control stage and assessment stage. It requires a series of stable and important steps to build up the whole operation of EFL teaching mechanism for college learner autonomy. The five stages of English autonomous learning, namely the vertical integration framework, is an important factor in determining the overall effectiveness and efficiency of the EFL teaching mechanism.

Specifically speaking, each stage has its own pedagogical significance, or say, technical, psychological, socio-cultural and critical significance[7], and the master of each stage for both learners and instructors is essential. For example, motivation stage is dealing with the psychological aspect of language learners, the environment stage is dealing with the socio-cultural aspect of language learners, and the control stage is dealing with the technical aspect of language learners. Thereby the dynamic process of the five stages in EFL teaching should be carried out step by step, and any absence of each stage will lead the whole process to incomplete and unsatisfying results.

Mobile multimedia in the vertical integration process is the most influential technical element, which helps foster the college English learning outcomes. The autonomous learning process via mobile multimedia is congruent with the common value proposed by constructivism and humanism. Mobile multimedia play a technical role and a cognitive role as well, so technical theories and linguistic theories should be highly considered and applied into the process of the design and implementation of mobile-multimedia assisted college English teaching. What's more, varieties of elements, such as information representation, individualization of teaching style, diversification of learning style and autonomy of English learning environment, are also very critical elements for English language learner autonomy in the vertical EFL teaching integration mechanism.

For a seamless and natural transition and connection of each stage of language learning, teachers should be prepared before each class and their focus should be placed on the mediate actions (i.e. supportive and servicing actions for students' learning)[8], including actions for language learner autonomy via mobile multimedia. Firstly, hardware technologies should be integrated into the learning environment so that language learners can finish efficient learning with the help of smart mobile devices, 4G wireless networks and intelligent software. Secondly, software technologies, for example, context recognition technology, should be integrated into effective learning environment, so that students can learn autonomously in mobile learning setting. By doing this, vertical integration of English language learning can be achieved efficiently and thoroughly. 


\section{Conclusion}

Changes in the teaching technologies by no means call for changes in teaching practice. Mobile multimedia have a far-reaching influence on the reforming and modernization of the education, especially English language instruction. The integration of mobile multimedia into foreign language teaching has brought about a new revolution in the realm of language education. The use of mobile multimedia enables teachers to give a vivid presentation and multi-dimensional interaction, which is other wise impossible in traditional class. The mobile-multimedia assisted EFL teaching supports the paradigm of the student-centered learning approach by integrating mobile multimedia into learning environment both horizontally and vertically and providing individual users with high level of control and interaction. Efforts should be made on the emergence of the technologies and the convergence of different autonomous learning stages, so as to enhance learners' all-around language capacities and English language autonomous learning abilities.

\section{Acknowledgement}

This work is part of the project of Research on the Cultivating Mechanism and Strategies for College English Autonomous Learning Ability via Mobile Multimedia, and the project of Development and Innovation Research on College English Learner Autonomy Mode in Ubiquitous Network Environment. This research was supported by the Fund of the Thirteenth Five-Year Plan of Education Sciences of Liaoning Province (Project No. JG16DB013), the fund of Liaoning Provincial Federation Social Science Circles (Project No. 2016lslktwx-01) and the fund of Liaoning Planning Office of Philosophy and Social Sciences (Project No. L15CWW001).

\section{References}

[1] Warschauer, M., Healey, D. Computers and Language Learning: An Overview[J], Language Teaching. 1998.

[2] Ministry of Education of the People's Republic of China, College English Curriculum Requirements[M]. Beijing: Higher Education Press, 2007.

[3] Liu Wenliang, A Study on Teaching Strategies of Multimedia Assisted College English Teaching [D]. Shanghai: Shanghai International Studies University, 2009.

[4] Piage, J., Equilibration of Cognitive Structures[M]. New York: Viking Press, 1997.

[5] Williams, M., Burden, R.L. Psychology for Language Teachers[M]. Cambridge: Cambridge University Press, 1997.

[6] Ren Huanhuan, Liu Yamei, Pedagogical Strategies on Fostering Learner Autonomy of College Students in Classroom Instruction[J]. Journal of Hubei Radio \& Television University, 2012 (05).

[7] Ren Huanhuan, Gao Peng, Development of English Autonomous Learning Skill Rating Scale for College Students[J]. Journal of Liaoning University of Science and Technology, 2012 (02).

[8] Ren Huanhuan, The Teacher’s Role: From “Knowledge Ontology” to "Knowledge Media”[J]. Theory and Practice of Education, 2016 (11). 